\title{
DOSSIÊ \\ Imagem, montagem e história em Videogramas de uma Revolução de Harun Farocki e Andrei Ujică
}

\author{
Image, montage and history \\ on Videograms of a Revolution \\ by Harun Farocki and Andrei Ujică
}

\author{
Barbara Mangueira do Nascimento \\ Doutoranda em História Social na Universidade Federal do Rio de Janeiro \\ orcid.org/0000-0002-5336-2481 \\ barbaramangueiran@gmail.com
}

\begin{abstract}
RESUMO: Este artigo propõe relacionar a análise do filme Videogramas de uma Revolução (1992), de Harun Farocki e Andrei Ujică, com a discussão presente nas obras de Jacques Rancière e de Georges Didi-Huberman sobre a relação entre imagem, montagem e história. Ambos autores, cada um a sua maneira, mobilizam a ideia de que as operações de montagem realizadas com as imagens permitem elaborar discursos sobre a história, bem como problematizar noções de tempo histórico. O filme escolhido para esta análise, realizado a partir de uma compilação de registros dos eventos que levaram a queda do regime comunista na Romênia, é perpassado por elementos pertinentes ao debate, sobretudo pela ênfase no papel das imagens técnicas nesse processo.
\end{abstract}

PALAVRAS-CHAVE: Imagem. Tempo Histórico. Montagem.

ABSTRACT: This article proposes to relate the analysis of the film Videograms of a Revolution (1992), by Harun Farocki and Andrei Ujică, with the discussion present in the works of Jacques Rancière and Georges Didi-Huberman on the relationship between image, montage and history. Both authors, each in their own way, mobilize the idea that the montage operations made with the images make it possible to elaborate discourses on history, as well as to problematize notions of historical time. The film chosen for this analysis, made from a compilation of records of the events that led to the fall of the communist regime in Romania, is permeated by elements pertinent to the debate, above all by the emphasis on the role of technical images in this process.

KEYWORDS: Image. Historical time. Montage.

\section{Introdução}

Videogramas de uma Revolução, dirigido por Harun Farocki e Andrei Ujică, é um filme de 1992 sobre os eventos ocorridos na Romênia no fim de 1989, que resultaram na queda do regime comunista no país liderado por Nicolae Ceauşescu. Neste artigo, busco relacionar a análise do filme com a discussão presente nas obras de 
Revista do Corpo Discente do Programa de Pós-Graduação em História da UnB

EM TEMPO DE HISTóRIAS | Brasília-DF | n. 37 | p. 423-432 | jul./dez. 2020.

ISSN 2316-1191

Jacques Rancière e de Georges Didi-Huberman sobre a relação entre imagem, montagem e história. Ambos autores, cada um a sua maneira, mobilizam a ideia de que as operações de montagem realizadas com as imagens permitem elaborar discursos sobre a história, bem como problematizar noções de tempo histórico. O filme escolhido para esta análise é perpassado por elementos pertinentes ao debate, sobretudo pela ênfase no papel das imagens técnicas nesse processo. Construído a partir de filmagens diversas, recolhidas de transmissões televisivas, câmeras de segurança, arquivos de jornalistas estrangeiros ou feitas pela própria população com câmeras amadoras, o resultado final permite entrever a complexidade da construção narrativa dos eventos perpassada pelos usos, circulação e reprodução das imagens. Veremos que mais do que uma organização sequencial de diferentes pontos de vista sobre um mesmo acontecimento, Videogramas de uma Revolução explora a importância daquilo que se mantém fora de tais enquadramentos. Portanto, a narrativa é construída pelo que se vê, mas sobretudo também a partir daquilo que sabemos estar para além das margens da visibilidade.

Na primeira cena do filme, vemos a filmagem de uma mulher ferida que relata a repressão que a polícia secreta da Romênia, a Securitate, incidiu sobre manifestantes opositores ao regime. A tônica do filme de explorar as formas como a produção e circulação das imagens pode interferir na construção narrativa dos eventos - e na própria realização dos mesmos, já aparece na forma como a mulher faz seu relato operar tanto como testemunho quanto como convocatória. Portanto, Farocki e Ujică mobilizam na relação com a imagem e a montagem diferentes concepções da palavra história. Não apenas a narrativa de um tempo então presente que em breve se tornará histórico, as imagens produzidas no momento buscaram influir diretamente no desenrolar dos acontecimentos, adicionando também o sentido de fazer história. A produção e circulação de imagens da história também produz história. Neste artigo, busco acrescentar o sentido mais disciplinar do termo, ao analisar o filme a partir de categorias do campo historiográfico.

\section{Contrapondo pontos de vista}

Os eventos registrados nos dias da revolta que levaram à queda do regime romeno foram os primeiros do tipo a serem televisionados em tempo real, marcando as formas como as imagens podem documentar e transmitir a história em um dado tempo presente (GENOUDET, 2014). O filme enfatiza as controvérsias da ideia de que a documentação por meio das imagens técnicas poderia mediar de forma realista esses registros. Ainda que a tarefa de crítica aos registros de imprensa tenha sido objeto da arte ao longo de todo o século XX, como é o caso da decomposição e recomposição por meio da montagem de fotografias jornalísticas feita pelos dadaístas ou nos Arbeitsjournal e Kriegsfibel de Bertold Brecht, no fim do século um novo elemento impõe uma mudança significativa: a difusão do acesso a aparatos tecnológicos ao cidadão comum, que pode filmar qualquer acontecimento que presencie até mesmo de dentro da sua própria residência. Se hoje essa possibilidade tomou a proporção que exacerba a condição da banalidade, ao final da década de 1980 ainda era incipiente e marcou a passagem da circunscrição dos anônimos como agentes históricos para 
Revista do Corpo Discente do Programa de Pós-Graduação em História da UnB

EM TEMPO DE HISTóRIAS | Brasília-DF | n. 37 | p. 423-432 | jul./dez. 2020.

ISSN 2316-1191

abarcá-los também na categoria de agentes do registro da história, não necessariamente enquanto disciplina, mas sem dúvidas como registro narrativo.

Como escreve Jacques Rancière (2014), a revogação da primazia dos acontecimentos e dos nomes próprios no fazer historiográfico que colocou em cena a vida dos anônimos foi o que permitiu a reivindicação da disciplina a seu pertencimento à era da ciência e da democracia. No entanto, ao afastar-se dos sujeitos tradicionais e dos antigos métodos de verificação dos acontecimentos, a pluralidade de narrativas que surge é perpassada por contradições dos diversos pontos de vista que tomam lugar, problematizando as ideias mesmas de sujeito e acontecimento (RANCIÈRE, 2014, p. 3). O autor destaca o interesse especial dado pela historiografia do século XX aos processos revolucionários e contrarrevolucionários, como se nestes fosse possível identificar a escrita de uma história comum que se expressa no segredo das multidões (Ibidem, p. 14). No filme de Farocki e Ujică, essa crença também é colocada em um lugar de fragilidade, pois vemos operar uma crítica que perpassa não só as filmagens televisivas - do sujeito de autoridade, mas também as amadoras - do homem comum com uma câmera nas mãos, demonstrando que a crítica das imagens deve ser um trabalho incansável.

Diversos são os momentos do filme em que a contraposição de diversos pontos de vista exacerba as contradições entre imagens que pertencem a um mesmo evento. As imagens fruto da cobertura de um canal de televisão local são combinadas com registros de diversas câmeras amadoras da população e por imagens de jornais estrangeiros. Percebemos que as contradições entre os registros dificultam a compreensão e consolidação de uma narrativa unívoca do evento. Para analisar essa estratégia estética e discursiva, recorro a categoria de montagem dialética proposta por Rancière no livro $O$ destino das imagens (2012). O autor propõe essa noção em contraponto à montagem simbólica, mas adverte que os termos em questão (dialética $\mathrm{e}$ simbólica) não são utilizados a fim de vincular as categorias a escolas ou doutrinas específicas, mas são mobilizados em um sentido conceitual mais amplo. A montagem dialética fragmenta o contínuo, distancia elementos que se atraem, cria "pequenas maquinarias do heterogêneo" (Ibidem, p. 66). O fundamento desse processo é o choque, que passa a ser seu próprio instrumento de medida e, ao ser organizado, cria uma nova ordem. A junção dos heterogêneos por meio do choque revela "o segredo de um mundo, isto é, o outro mundo, no qual a lei se impõe por trás das aparências" (Ibidem, p. 67). Ainda que o autor diferencie a montagem dialética da simbólica (esta buscaria estabelecer analogias por meio da aproximação dos incompatíveis, não opondo mundos, mas criando o comum), acrescenta que as duas lógicas também se entrelaçam. A montagem, de qualquer forma, organiza um choque e/ou constrói um contínuo, ainda que por métodos e resultados distintos. É isso que permite a Rancière equiparar a estratégia da montagem à própria história: "o espaço do choque e do contínuo podem ter o mesmo nome, História” (Ibidem, p. 70).

Logo nos primeiros minutos do filme, vemos uma filmagem de uma câmera amadora que do alto de um prédio em Bucareste busca registrar algo que se passa no plano de fundo ao longe. As limitações técnicas se unem ao difícil ponto de vista de quem filma, pois o objeto buscado encontra-se ocultado por outros prédios e árvores. Enquanto nos esforçamos para identificar o que a câmera busca, uma narradora em off 
Revista do Corpo Discente do Programa de Pós-Graduação em História da UnB

EM TEMPO DE HISTóRIAS | Brasília-DF | n. 37 | p. 423-432 | jul./dez. 2020.

ISSN 2316-1191

induz a perceber uma marcha de manifestantes. Em seguida, as imagens são da televisão local que transmite um comício de Nicolae Ceauşescu no momento em que é interrompido por um tumulto. A voz feminina que narra tem um tom de objetividade que nos levados rapidamente a suspeitar das informações que nos são mostradas. Em um primeiro momento do filme, as imagens amadoras geram a suspeita de que outras coisas se passavam à revelia das filmagens oficiais. A possibilidade de que diversos atores possam registrar o mesmo evento de diferentes posições (físicas e sociais) enfrenta a soberania das imagens institucionais. Georges Didi-Huberman (2015, p. 206), ao escrever sobre Farocki, destaca que o cineasta toma das imagens institucionais aquilo que elas não querem mostrar, fazendo vir a tona as operações de poder na distribuição do visível e restituindo, desta forma, as imagens à esfera pública.

Rancière (2015) estabelece o vínculo entre as modificações do campo da historiografia previamente mencionadas e o desenvolvimento dos aparatos das imagens técnicas como a possibilidade de unir em um mesmo sujeito aquele que age na história e ao mesmo tempo a registra. $\mathrm{O}$ exemplo utilizado pelo autor para sustentar essa posição, no livro Figuras da História, é justamente a cena acima mencionada do sujeito que filma a marcha desde uma janela em Bucareste. Ele acrescenta que a novidade dos registros alternativos não se reduz à documentação, mas também interfere na própria criação do acontecimento: "se o cria é talvez em virtude de seu próprio poder de tornar histórica qualquer aparição detrás de uma janela" 1 (RANCIÈRE, 2015, p. 32).

O historiador Adrien Genoudet (2014) também estabelece o paralelo entre o filme e questões pertinentes para a prática atual da disciplina histórica, pois os diretores questionam a visualidade da história e as implicações da escrita da história por imagens. São as próprias questões visuais do século XX que estão implicadas na narrativa do filme, na forma como as imagens se inscrevem em um determinado contexto de realização ao mesmo tempo em que deslocam-se para fora através da reutilização, manipulação e recontextualização. O que o autor chama de época da efervescência das imagens aparece no filme como uma crítica ao modo geral como os modos de ver e ler a história e as imagens acontecem no fim do século. Essa percepção sobre a relação entre o filme e os modos de ver, ler e fazer história está em sintonia com o que propõe o historiador Robert Rosenstone (2010), que buscou demonstrar como a produção cinematográfica, em suas diferentes formas, também oferece uma leitura própria e contribuições ao um debate mais amplo sobre o fazer historiográfico. Desta forma, em Videogramas da Revolução não está presente apenas uma reflexão sobre os acontecimentos filmados a época, mas também sobre os próprios meios de documentar, narrar, criar reflexões sobre a história e, mais além, influir no desdobramento da mesma.

1 Tradução da autora. "S’il le crée, c'est peut-être em vertu de son propre pouvoir de rendre historique n'importe quelle apparition derrière une fenêtre". 
Revista do Corpo Discente do Programa de Pós-Graduação em História da UnB

EM TEMPO DE HISTÓRIAS | Brasília-DF | n. 37 | p. 423-432 | jul./dez. 2020.

ISSN 2316-1191

\section{Para além das margens da visibilidade}

Essa dupla operação em relação à narrativa, registrar enquanto interfere, também se dá pelas características estéticas mobilizadas no jogo de enquadramentos que dá a ver ao mesmo tempo em que também esconde. $\mathrm{O}$ paradoxo das imagens, que sempre marcam uma inclusão e uma exclusão do que se pode ver, opera no filme de modo a questionar noções do real. Não apenas porque um enquadramento significa uma parcialidade, um recorte determinado, mas porque mesmo o que está no campo da visibilidade coloca o real em questão. Nas imagens, há o que foi presumidamente intencional no registro, mas também há o que transborda e muitas vezes contradiz essa intencionalidade. É o conflito sobre a possibilidade em si de buscar o real por meio do enquadramento das câmeras, ou seja, pela natureza técnica das imagens, que perpassa a noção crítica de ler e fazer história presente no filme.

Retomando a discussão apresentada por Rancière em Figuras da História (2015), o cinema documental tem a potencialidade de fazer combinações entre o que é dado a ver explicitamente e o que fala por si através da mudez, seja por meio dos elementos que são capturados na filmagem de forma não intencional, seja pela percepção do que permanece fora dos enquadramentos. $O$ autor evoca as noções de documento e monumento para argumentar sobre essa complexidade dos registros, que tanto a história que ao longo do século XX ao expandir as possibilidades de fontes para além dos documentos oficiais, quanto as operações da arte, ecoam a dinâmica romântica da constante conversão entre significante e insignificante. Nessa distinção, o documento é o que surge da intenção manifesta de registrar e informar, enquanto o monumento é o que se torna matéria para a história (e para a arte) justamente por não ter a intenção de sê-lo, "o que fala sem palavras, o que nos instrui sem intenção de instruir-nos, o que carrega memória pelo fato mesmo de não preocupar-se senão por seu presente" 2 . Entretanto, isso não quer dizer que essas categorias encontrem-se em objetos separados. Elas trocam constantemente de lugar e se cruzam muitas vezes em um mesmo objeto. Em Videogramas de uma Revolução esse jogo está constantemente presente e é a condição fundamental que permite pensar a história a partir de suas imagens.

Farocki, que também produziu reflexão teórica escrita sobre o universo das imagens técnicas, no texto $O$ que é um estúdio de edição, publicado na revista Filmkritik em 1980 e reproduzido na íntegra no livro Desconfiar das Imagens (2013), argumenta que é na etapa da edição em que é possível observar a autonomia das imagens, pois é quando é possível identificar que a filmagem registrou elementos antes não percebidos (FAROCKI, 2013, p. 81). É então necessário realizar um trabalho com esse novo, ver as imagens para além delas mesmas, em um sentido próximo ao do historiador que faz falar testemunhos mudos da vida ordinária (RANCIÈRE, 2015). Esse trabalho de edição em Videogramas de uma Revolução consiste na montagem do material de modo a explicitar aquilo que as edições anteriores, realizadas pelos atores envolvidos nos registros da época, tentaram ocultar. Desta forma, Farocki critica os cortes e montagens utilizando os mesmos procedimentos. Segundo Didi-Huberman

2Tradução da autora. "Le monument est ce qui parle sans mots, ce que nous instruit sans intention de nous instruire, ce qui porte mémoire par le fait même de ne s'être soucié que de son présent”. 
Revista do Corpo Discente do Programa de Pós-Graduação em História da UnB

EM TEMPO DE HISTóRIAS | Brasília-DF | n. 37 | p. 423-432 | jul./dez. 2020.

ISSN 2316-1191

(2015, p. 209), esse processo ocorre de forma não a se apropriar de um ou outro ponto de vista, mas de devolvê-los ao público de modo dialético, como uma maneira de emancipar as imagens. Restituir as imagens ao bem comum é uma forma de criticar as instituições que buscam determinar o que podemos e o que não podemos ver.

Em outro texto publicado na revista Filmkritik em 1981, Plano/contraplano - A expressão mais importante da lei do valor cinematográfico, Farocki (2013, p. 83) define os termos corte e montagem a partir do nível de evidência desses procedimentos. Enquanto a montagem é claramente reconhecível, o corte tenta passar despercebido (ainda que seja possível questionar essa diferença pelos recursos tecnológicos do presente, para a análise do filme em questão essa leitura é pertinente). Para o cineasta, ambos mecanismos são análogos aos elementos estruturadores de um texto, ditando o ritmo e dando ênfase em determinados aspectos em detrimento de outros. No cinema, essa estratégia rítmica encontra sua expressão na sucessão de planos e contraplanos. Ainda que em Videogramas de uma Revolução esse recurso seja utilizado pelos próprios diretores, há uma cena na qual é evidenciada a quebra dessa lógica estruturante pelo operador da câmera televisiva no momento em que os objetivos perseguidos por meio dela se frustram. A cena é parte do comício de Ceauşescu, gravada no formato clássico dos filmes de propaganda política que utilizam o modelo de plano e contraplano para costurar uma relação de harmonia e reciprocidade entre a figura do líder e o povo. Entretanto, quando o tumulto em meio à multidão perturba a continuação do comício, não é mais desejável que as câmeras revezem a filmagem entre o governante e o público. A imagem então congela na figura de Ceauşescu, até que se por fim a transmissão é interrompida.

Genoudet (2014) identifica três questões no filme que decorrem da relação entre a história e sua visibilidade: o que se mostra, como se mostra e o que podemos ver. Os diretores, na leitura do autor, apontam para o fato de que não existe apenas uma composição do que se pode ver, mas também uma certa imposição que precisa ser analisada por meio de uma montagem crítica. As diferentes estratégias de montagem utilizadas ao longo do filme permitem analisar como os cortes e edição condicionam determinada leitura. Farocki e Ujică buscam apontar como a visibilidade dos acontecimentos depende da invisibilidade de parte deles, pois da maneira como a montagem é construída somos convencidos de que os conteúdos ocultos ou suprimidos continuam de alguma forma presentes. A impossibilidade em desconsiderar o que está fora do campo de visão é marca da construção narrativa do filme. Os cortes e intervalos, escreve Thomas Elsaesser (2010, p. 111), deixam uma conexão ausente, um entre, uma imagem que falta.

O jogo entre visibilidade e invisibilidade presente em Videogramas de uma Revolução é perpassado pela demonstração de que os cortes intencionais, produzidos pelas imagens oficiais no momento dos tumultos, falham na tentativa de ocultar o que se passa. Genoudet (2014) defende que eles chegam a provocar o efeito contrário, pois a percepção da ausência de uma imagem nos leva a entrever que algo acontece para fora das margens do enquadramento. Ainda nas imagens do comício de Ceauşescu, quando o discurso é interrompido e a câmera não é direcionada para a razão da interrupção (ouvimos ruídos de um tumulto), o governante dirige seu olhar para um ponto específico ao longe e seu semblante é transformado por completo. Ele vê algo que não 
Revista do Corpo Discente do Programa de Pós-Graduação em História da UnB

EM TEMPO DE HISTóRIAS | Brasília-DF | n. 37 | p. 423-432 | jul./dez. 2020.

ISSN 2316-1191

podemos ver, algo que as filmagens televisivas se recusaram a registrar. Isso não impede, contudo, de que o espectador possa de certa forma ver o próprio acontecimento através do signo de sua ausência, pela perturbação expressa nos olhos de Ceauşescu. Em Farocki o papel do corte e da montagem nas imagens cinematográficas é, como mencionado anteriormente, manipular o ritmo e o tempo por meio da alternância entre fazer ver e tornar invisível.

Genoudet (2014) destaca que o espaço de visibilidade que as imagens técnicas oferecem ao olhar tem centralidade na reflexão sobre a relação entre as imagens e a história. Farocki e Ujică fazem desse espaço de visibilidade aberto à polissemia. O autor defende que a maneira como as imagens são apresentadas é uma forma de ampliar o campo de visão do espectador, dando origem à visualidade do acontecimento. Assim como em outras obras de Farocki, o espectador é convidado a ver e rever as imagens é colocada a necessidade de entendê-las, temporalmente e intimamente, como objetos em movimento (GENOUDET, 2014). Mobilizando a mesma ideia em outras palavras Elsaesser (2010) escreve que para Farocki encontrar uma imagem é de certa forma reencontrá-la. Esse movimento de revisitar as imagens, de desconfiar das imagens, coloca em cena a importância das expectativas de quem vê. Isso é o que se busca mobilizar tanto pelas imagens originais televisivas no momento do acontecimento, quanto pelo próprio filme Videogramas de uma Revolução. Apenas é possível construir uma narrativa sobre a história se esse jogo de expectativas se mantém em constante atividade.

\section{Montagem, experiência e expectativa}

Esse tipo de efeito também é analisado teoricamente por Farocki no texto Um corte ou a vingança da televisão, publicado no periódico alemão die tageszeitung em 1989 (FAROCKI, 2013, p. 107). O texto comenta a transmissão televisiva do acidente que ocorreu na base aérea de Ramstein durante uma demonstração aérea em 1988. No exato momento em que a imagem capturaria a colisão dos aviões, um corte na transmissão foi realizado, trocando a imagem para a de uma coletiva de imprensa na cidade de Bonn. Farocki observa nesse corte na transmissão o interesse da emissora mais em ilustrar processos políticos que veicular conteúdo informativo. As duas filmagens colocadas em sequência significariam estratégia de sobrepor a imagem da colisão à imagem da política de Bonn. No momento em que espera-se ver um choque, a expectativa esbarra na imagem do entrevistado.

A montagem de elementos heterogêneos como potencialidade para expor a complexidade de um tempo também foi motivo de estudo em diversas obras de Georges Didi-Huberman. Em A imagem sobrevivente: história da arte e o tempo dos fantasmas segundo Aby Warburg (2013a) e em Atlas ou A Gaia Ciência inquieta (2013b), são inúmeros os apontamentos que analisam a montagem como proposta epistemológica para o conhecimento da história. No primeiro, o estudo do legado e das práticas de Aby Warburg delineia a prática da montagem como modo de fazer uma observação dialética das imagens. O Atlas Mnemosyne do pensador alemão que é definido como um trabalho de montagem não só com as imagens, mas também com a história. A técnica da montagem é lida como um como o mecanismo para colocar o pensamento em 
Revista do Corpo Discente do Programa de Pós-Graduação em História da UnB Em TEMPO dE HISTÓRIAS | Brasília-DF | n. 37 | p. 423-432 | jul./dez. 2020.

ISSN 2316-1191

movimento justamente nos pontos onde a história e as palavras se detinham e falhavam (2013a, p. 20). Por esse recurso, Warburg podia compreender as imbricações e as contradições das imagens, inserindo-as em narrativas complexas que extrapolavam os limites de uma história essencialmente contextualista. Sobrepor heterogêneos permitia detectar que "as diferenças desenham configurações e que as dessemelhanças criam, juntas, ordens não percebidas de coerência” (2013a, p. 399). Nesse processo, a criação de distâncias de sentidos e significações é fundamental. Assim como defende Farocki, Didi-Huberman entende que a montagem permite um movimento rítmico dos elementos em jogo (2013a, p. 420).

Pensando nas formulações de Didi-Huberman, podemos com o exemplo da quase-imagem da colisão entre os aviões observar que uma imagem fragmentada, ou submetida a um corte, ainda que supostamente sob a imposição de limites (bordas), pode ter estes mesmos limites expandidos através de uma montagem, evidenciando que as imagens não terminam em si mesmas (DIDI-HUBERMAN, 2013b, p. 34). O autor ao estudar a prática do Atlas, destaca como o recurso da montagem faz evidenciar as lacunas e fraturas que as imagens carregam intrinsecamente, inquietando nosso olhar, e nossa razão, diante da percepção de que as imagens não mostram apenas coisas imediatamente presentes à vista, mas também as ausentes que podemos prever e entrever (Ibidem, p. 41). A comparação que Farocki estabelece no texto anteriormente citado com a continuidade mental que formulamos para a imagem da colisão com a persistência das imagens na retina, aqueles vultos espectrais que, mesmo quando o objeto já está ausente, continuamos a enxergar. Mesmo que interrompida, a imagem da colisão se completa na visão e é induzida à associação com o conteúdo da imagem que toma o seu lugar. Farocki, como crítico das imagens institucionais, não vê casualidade nessa operação, mas sim um jogo intencional das formas de operar o poder por meio da manipulação do visível.

Em Videogramas de uma Revolução, a montagem de narrativas é a um só tempo a construção de um mosaico de pontos de vistas e a crítica dos mesmos. A ideia de montagem está na própria raiz da ideia de cinema. Sem dúvidas por essa razão Rancière deu tamanha atenção às imagens cinematográficas. $O$ autor define as imagens do cinema como operações e relações entre o dizível e o visível, formas de jogar com o antes e o depois na qual a fragmentação das imagens não é uma simples quebra do encadeamento narrativo, mas uma forma de colocar em curso um jogo duplo em relação a esse encadeamento. Isso ocorre, em consonância com o que foi dito anteriormente, por meio de um jogo com as expectativas em relação aos efeitos das imagens (RANCIÈRE, 2012, p.14). Inserindo nesse debate a relação experiências vividas e as expectativas projetadas, sobretudo a partir do modo pelo qual Reinhart Koselleck (2006) mobiliza essas categorias para pensar a complexidade do tempo histórico (espaços de experiência/horizontes de expectativa), podemos observar como em Videogramas de uma Revolução o cruzamento simultâneo entre as experiências vividas e as expectativas geradas pelas imagens produzidas ocorre de forma com que se alterem mutuamente. A projeção das expectativas, que se expressa nas diferentes intencionalidades dos atores que registram os acontecimentos e na transmissão ao vivo das imagens televisivas, altera as condições da experiência. No entanto, uma não é mera consequência da outra, como uma relação estática, ao contrário, essas categorias 
Revista do Corpo Discente do Programa de Pós-Graduação em História da UnB

EM TEMPO DE HISTÓRIAS | Brasília-DF | n. 37 | p. 423-432 | jul./dez. 2020.

ISSN 2316-1191

se sobrepõem, se contradizem e se modificam a partir dessas tensões. A proposta de pensar passado e futuro não como apenas como acepções cronológicas, mas como categorias de análise histórica de Koselleck, se relaciona com o que observamos no filme. O autor escreve: "o futuro histórico nunca é o resultado puro e simples do passado histórico" (KOSELLECK, 2006, p. 312). Rancière (2015) destaca a importância em considerar o poder que as imagens registradas por uma câmera tem de mudar o entendimento sobre um determinado acontecimento inclusive para aqueles que o vivenciaram. Isso pode ocorrer, muitas vezes, pela simples estratégia de ocultar os laços que vincula os eventos a um contexto maior. Farocki e Ujică, a partir das edições e montagem das filmagens, utilizam por diversas vezes o recurso de sobrepor um quadro pequeno ao quadro geral, apresentando simultaneamente múltiplas narrativas. Desta forma, os diretores estruturaram seu próprio texto e criam os laços que desejam estabelecer entre os acontecimentos. Farocki argumenta no já citado texto O que é um estúdio de edição, que a edição é o que permite transformar o balbuciar em uma retórica (FAROCKI, 2013, p.82).

Se as imagens utilizadas no filme extrapolam o papel de registro dos eventos, atuando no próprio desenvolvimento dos mesmos, é porque não apenas seu contexto de produção é relevante, mas também o de circulação, tema pertinente também a outros trabalhos de Farocki. As tentativas frustradas de utilizar as imagens como indício de verdade, validando algumas narrativas em detrimento de outras, é um propósito perturbado pela própria natureza técnica dos registros. As palavras ao contrário, escreve Farocki "simplesmente, são mais fáceis de manejar que as imagens, é mais fácil submetê-las a regras, transmiti-las e adaptá-las, pelo qual gozam de uma vantagem de produção diante das imagens" (2013, p.130). As imagens são mais resistentes a leituras unilaterais, ideia corroborada por Rancière ao defender que é somente no domínio da retórica que as imagens são suficientes para provar determinada leitura ou construção narrativa, pois fora desse domínio, contentam-se em mostrar e promover memória (2015).

É por essa razão que em Videogramas de uma Revolução as imagens são, citando Elsaesser, pensadas a partir da observação "frente e verso" das mesmas, nas quais Farocki consegue reposicioná-las de modo a entrever uma confiança nas reviravoltas (ELSAESSER, 2010). Essa operação ocorre sobretudo ao interrogar os próprios espectadores acerca de sua posição como seres políticos diante das imagens. O filme aborda os usos políticos das imagens em um contexto de conflito social, no entanto também coloca a questão de como podemos tomar posição diante das imagens do mundo de um modo geral. Didi-Huberman começa o primeiro livro da série $O$ Olho da História, que se chama Quando as imagens tomam posição (2017), com a afirmação: "Para saber é preciso tomar posição" (DIDI-HUBERMAN, 2017, p. 15). É necessário posicionar-se eticamente diante do que buscamos saber, implicar-se, decidir. O filme de Farocki e Ujica nos interroga sobre essas questões. As imagens que apresentam "desmontam o mundo" (Idem, 2015, p.221) ao mesmo tempo em que o remonta para que possamos vê-lo de forma crítica. O trabalho com as imagens de um evento histórico na obra de Farocki é o confrontar constante de um plano com um contra-plano, ou como escreve Didi-Huberman, a consciência de que para fazer uma crítica das imagens é imprescindível a produção de imagens críticas (Ibidem, p. 28). 
Revista do Corpo Discente do Programa de Pós-Graduação em História da UnB

EM TEMPO DE HISTóRIAS | Brasília-DF | n. 37 | p. 423-432 | jul./dez. 2020.

ISSN 2316-1191

\section{Referências}

DIDI-HUBERMAN, Georges. A Imagem Sobrevivente: história da arte e tempo dos fantasmas segundo Aby Warburg. Rio de Janeiro: Contraponto, 2013.

. Atlas ou A Gaia Ciência Inquieta. O olho da história 3. Lisboa: KKYM + EAUM, 2013.

. Quando as imagens tomam posição. O olho da história 1. Belo Horizonte: Editora UFMG, 2017.

. Devolver uma imagem. In: ALLOA, Emmanuel (org.). Pensar a imagem. Belo Horizonte: Autêntica Editora, 2015.

ELSAESSER, Thomas. Harun Farocki: cineasta, artista, teórico da mídia. In: BORGES, Cristian; MOURÃO, Maria Dora G.; MOURÃO, Patrícia (org). Harun Farocki - por uma politização do olhar. São Paulo: Cinemateca Brasileira, 2010.

FAROCKI, Harun. Desconfiar de las imágenes. Buenos Aires: Caja Negra, 2013.

GENOUDET, Adrien. Visualité de l'historie dans Vidéogrammes d'une révolution de Harun Farocki et Andrej Ujica, 2014. Disponível em: https://zintv.org/outil/visualitede-lhistoire-dans-videogrammes-dune-revolution-de-harun-farocki-et-andrej-ujica/ (acesso 17/09/2020).

KOSELLECK, Reinhart. Futuro passado: contribuições à semântica dos tempos históricos. Rio de Janeiro: Contraponto, 2006.

RANCIÈRE, Jacques A partilha do sensivel: estética e política. São Paulo: EXO experimental org.; Editora 34, 2009.

. Figures de l'histoire. Paris: Presses Universitaires de France, 2015.

. O destino das imagens. Rio de Janeiro: Contraponto, 2012.

2014.

. Os nomes da história: ensaio de poética do saber. São Paulo: Editora Unesp,

ROSENSTONE, Robert A. A história nos filmes / Os filmes na história. São Paulo: Paz e Terra, 2010. 